\section{A CONSTRUÇÃO DE VIVÊNCIAS COMO METODOLOGIA DE ENSINO DE CIÊNCIAS: ENSINANDO ALUNOS DO ENSINO FUNDAMENTAL POR MEIO DE ATIVIDADES LÚDICAS}

\author{
The Life Experience Construction as a Science Teaching Methodology: Teaching \\ Elementary School Students through Playful Activities
}

La construcción de experiencias como una metodología de enseñanza de ciencias: enseñanza de estudiantes de primaria a través de actividades lúdicas

\begin{abstract}
Resumo: A Construção de Vivências é uma metodologia de ensino que se baseia em métodos de ensino por meio de jogos narrativos e interpretativos e estabelece uma abordagem humanista nos processos de ensino e aprendizagem, se pautando no desenvolvimento da experiência de vida, do lúdico enquanto estrutura organizacional das atividades e do capital cultural enquanto mediador do conhecimento e da aprendizagem. Esta metodologia foi aplicada com alunos de duas escolas localizadas na região norte do Estado do Paraná, que por meio de partidas de RPG (Role Playing Games) puderam se apropriar de vários conceitos científicos e aplicar saberes formais que vinham recebendo de suas professoras durante o ano letivo no período normal de ensino, tendo a oportunidade de ressignificar estes saberes por meio da Construção de Vivências. Das atividades realizadas foram coletados e analisados três diferentes instrumentos por meio da Análise de Conteúdo. Os resultados demonstraram que a Metodologia de Construção de Vivências cumpriu com o seu objetivo de desenvolver um pensamento crítico e significativo relacionado com os conteúdos científicos ensinados em sala de aula.
\end{abstract}

Palavras-Chave: Metodologia de Ensino; RPG e Ensino de Ciências; Aprendizagem por meio do lúdico.

Abstract: The Life Experience Construction is a teaching methodology that is based on teaching methods through narrative and interpretive games and establishes a humanistic approach in the teaching and learning processes, based on the development of life experience, of playfulness as the organizational structure of activities and cultural capital as a mediator of knowledge and learning. This methodology was applied to students from two schools located in the northern region of Paraná State in Brazil, who, through RPG games were able to appropriate various scientific concepts and apply formal knowledge that they had been receiving from their teachers during the school year. In the normal teaching period, having the opportunity to reframe this knowledge through the Construction of Experiences. From the activities carried out, three different instruments were collected and analyzed through Content Analysis. The results showed that the Life Experience Construction Methodology fulfills its objective of developing a critical and meaningful thinking related to the scientific contents taught in the classroom.

Keywords: Learn Methodology; RPG and Sciences Teaching; Playfulness Learning

Resumen: La construcción de experiencias es una metodología de enseñanza que se basa en métodos de enseñanza a través de juegos narrativos e interpretativos y establece un enfoque humanista en los procesos de enseñanza y aprendizaje, basado en el desarrollo de la experiencia de la vida, del juego como la estructura organizativa de actividades y capital cultural como mediador del conocimiento y el aprendizaje. Esta metodología se aplicó a estudiantes de dos escuelas ubicadas en la región norte del Estado de Paraná em el Brasil, quienes, a través de juegos de rol pudieron apropiarse de varios conceptos científicos y aplicar el conocimiento formal que habían estado recibiendo de sus maestros durante el año escolar. en el período normal de enseñanza, tener la oportunidad de replantear este conocimiento a través de la Construcción de Experiencias. A partir de las actividades realizadas, se recopilaron y analizaron tres instrumentos diferentes a través del Análisis de Contenido. Los resultados mostraron que la Metodología de Construcción de Experiencias cumple su objetivo de desarrollar un pensamiento crítico y significativo relacionado con los contenidos científicos que se enseñan en el aula.

Palabras clave: Metodología de Enseñanza; Juego del rol y Enseñanza de Ciencias; Aprendizaje a través del Lúdico.

\section{AUTORES:}

FERNANDO GIANETTI FIORIN

ORCID 0000-0002-2302-7068

${ }^{1}$ Universidade Federal de Santa Catarina (UFSC)

AGNALDO ARROIO²

ORCID 0000-0001-9242-5337

${ }^{2}$ Universidade de São Paulo (USP)

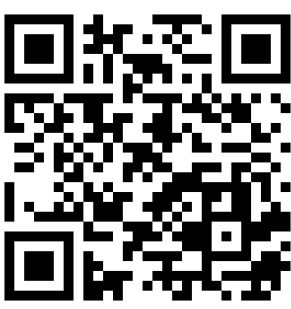

Para citar este artigo:

FIORIN, F. G.; ARROIO, A. A construção de vivências como metodologia de ensino de ciências: ensinando alunos do ensino fundamental por meio de atividades lúdicas. Revista Eletrônica Ludus Scientiae, Foz do Iguaçu, v. 4, n. 2, p. 28-42, 2020. 


\section{INTRODUÇÃO}

Desde a década de cinquenta, quando os currículos educacionais passaram por reformas, a disciplina de ciências tem sido ensinada da mesma maneira, com aulas expositivas e descontextualizadas (KRASILCHIK, 2004). Essa forma de ensinar se tornou preponderante nas escolas da educação básica, marcadas por metodologias de ensino fundamentadas em um pensamento tecnicista, preocupado com a formação de mão de obra especializada para atuar nas áreas científicas e tecnológicas, uma necessidade que se tornou evidente conforme os governos militares forçavam um processo de industrialização nacional (ARMSTRONG; BARBOSA, 2012).

Segundo Bizzo (2012), a partir da década de noventa houve um desejo por parte dos educadores brasileiros de estabelecer uma reforma em torno dos conteúdos e métodos de ensino que vigoravam desde as décadas anteriores, pautado principalmente em outros modelos de ensino, particularmente nos modelos espanhóis. Estas novas abordagens tinham como enfoque trabalhar as competências e as habilidades, num movimento que buscava suplantar o pensamento tecnicista.

Com estas reformas educacionais decorrentes da década de noventa, novas metodologias de ensino puderam se desenvolver, buscando não apenas a capacitação dos alunos na disciplina de ciências, mas também sua capacidade de compreender a linguagem científica e a sua contextualização (CHASSOT, 2010). A metodologia de Construção de Vivências se apresenta dentro de tal contexto.

Segundo Armstrong e Barbosa (2012), as metodologias de ensino se estabelecem por meio de situações do processo de ensino e aprendizagem em que um conjunto de métodos é aplicado no processo pedagógico a fim de conduzir a prática educativa do professor.

Dentro de tal paradigma, a metodologia de construção de vivências se utiliza de métodos narrativos para a sua aplicação em sala de aula ou outros ambientes de aprendizagem, dentre eles o Role Playing Game (RPG), o Live Action Role Playing (LARP), os Jogos de Papéis e a Contação de Histórias. Por meio destes métodos narrativos, espera-se que a Construção de Vivências permita o desenvolvimento do pensamento crítico dos educandos (ARMSTRONG; BARBOSA, 2012) que é a capacidade de compreender os conteúdos científicos aprendidos em sala de aula e a sua consonância com as teorias e práticas constituintes da realidade destes educandos.

Este trabalho tem como objetivo apresentar a Metodologia de Ensino de Construção de Vivências e descrever sobre sua utilização em duas turmas do nono ano do ensino fundamental, uma inserida em uma escola pública estadual, localizada na cidade de Bandeirantes, no norte pioneiro do Paraná, e outra em uma escola particular, localizada em Londrina, situada na região norte do Paraná. Cada uma das turmas contou com um total de 16 participantes, que se compromissaram em tomar parte de atividades de contraturno durante oito sessões diferentes, com uma duração de duas horasaula por sessão. Os 16 alunos de cada escola a participar vieram de turmas maiores que funcionavam durante o período matutino e todos foram escolhidos pelas equipes pedagógicas de cada escola, que por sua vez aconselharam a atividade durante o contraturno, se interessando na atividade de Construção de Vivências como um tipo de implementação à formação desses alunos.

Esta pesquisa visou apresentar conteúdos científicos para estes alunos por meio do RPG de Mesa, um dos métodos de ensino englobados dentro da metodologia proposta, e permitir que estes pudessem desenvolver um maior entendimento sobre assuntos como Astronomia, Física, Química, Biologia, buscando, desta forma, desenvolver um conhecimento crítico e relevante para a sua formação enquanto alunos do Ensino Fundamental anos finais.

\section{METODOLOGIA DE CONSTRUÇÃO DE VIVÊNCIAS}

Dentro do que Armstrong e Barbosa (2012) caracterizam como metodologia e método de ensino, a Construção de Vivências é uma metodologia de ensino, isto é, uma atividade que engloba vários métodos de se trabalhar os conteúdos científicos organizados em um conjunto de eixos que 
possuem a finalidade de apresentar um assunto e conduzir uma mediação entre o conhecimento e o educando, sendo que todos estes métodos têm em comum o fato de explorarem a capacidade narrativa e interpretativa tanto do educador como dos educandos que fazem parte da atividade que pode ser empregada tanto em espaços formais como não formais de ensino.

Esta metodologia se sustenta em um tripé formado por três conceitos essenciais: I) a experiência-sentido da atividade; II) a estrutura lúdica da atividade e III) as condições sociais do educando que se mostram relevantes para que ocorra a aprendizagem. Tais conceitos serão detalhados a seguir.

A experiência e o sentido da atividade se baseiam no que Larrosa (2016) conceitua como a capacidade de viver aquilo que se passa com cada de um de nós. O conceito apresentado neste trabalho está distante da concepção mais compreendida da mesma como experimentos ou experimentações. Experiência é, para este autor, a capacidade de se vivenciar aquilo que acontece conosco e que nos permite experimentar novos significados e significantes. Para Larrosa (2016), a nossa sociedade está presa dentro de uma concepção equivocada de que a informação e, por meio desta, a formação de uma opinião, são suficientes para formar indivíduos que consigam lidar com a realidade. Apenas por meio da capacidade de se experienciar aquilo que nos ocorre e refletir sobre tais experiências podemos desenvolver uma compreensão mais crítica da realidade que nos cerca. E esta experiência, portanto, precisa estar presente nas aulas de ciências.

Já a estrutura lúdica da atividade precisa ser estabelecida por meio da compreensão dos métodos de ensino que se pretende adotar, tendo um conhecimento amplo e bem fundamentado para que exista uma segurança por parte do educador quando se utilizar da metodologia, pois cada atividade lúdica é fundamentada dentro dos seus conjuntos de regras, o que não é diferente quando se trata de jogos narrativos como o RPG e o LARP. Huizinga (2014) se refere ao conhecimento das regras de qualquer atividade lúdica como Círculo Mágico, o que para este autor é a capacidade de compreensão de cada participante das regras de tal atividade, compreendendo não apenas a sua mecânica, mas também os seus aspectos sociais. Para Brougère (2010) os aspectos sociais são extremamente importantes para a fundamentação da atividade lúdica enquanto um elemento constitutivo de uma atividade de ensino e aprendizagem, pois por meio do lúdico vários aspectos sociais são compreendidos pelos seus participantes, em especial a existência de regras e a compreensão do processo de relação entre os participantes para que a atividade, mesmo que realizada de maneira competitiva, possa se dar de maneira satisfatória para todos que a executam.

Por conseguinte, as condições sociais inseridas na Metodologia da Construção de Vivências são abarcadas por aquilo que Bourdieu (2015 e 2012) conceitua como Capital Cultural. Para este filósofo cada indivíduo possui uma formação cultural relacionada com as possibilidades que se apresentam, seja nas suas relações sociais, seja nas suas capacidades econômicas. As experiências vivenciadas por cada indivíduo possibilitam uma formação cultural que o instrumentaliza para lidar com os aspectos humanos inseridos em nossa sociedade, como saber apreciar uma obra de arte ou algum tipo de música erudita, ter familiaridade com diferentes atividades lúdicas e midiáticas e também possuir uma condição mais favorável para a sua formação cognitiva. Quanto mais capital cultural um indivíduo possui, mais fácil se torna para compreender atividades que se realizem num escopo diferente daquele com o qual o mesmo possa estar familiarizado. Então, obviamente, quanto mais desenvolvido um indivíduo se apresenta nas questões lúdicas, maior é a capacidade de compreender atividades realizadas por meio de jogos narrativos e interpretativos.

Assim sendo, a Metodologia de Construção de Vivências se respalda por meio da formação de experiências significativas que, de muitas formas, também se apresentam por meio de atividades lúdicas narrativas e interpretativas e que podem ser melhor compreendidas conforme o capital cultural que cada educando possui quando participa destas atividades.

Como discutido inicialmente na Introdução e embasado em Armstrong e Barbosa (2012) em relação ao que se entende como metodologia e método de ensino neste trabalho, dando corpo para 
esta metodologia estão as diferentes atividades lúdicas que se centram em métodos narrativos e discursivos. Estas atividades, quando englobadas dentro da Metodologia de Construção de Vivência, ganham o caráter de método de ensino, pois possuem o caráter intencional de proporcionar meios de se ensinar os conteúdos científicos mais diversos possíveis que possam fazer parte do corpo de saberes considerados essenciais para a aprendizagem dos educandos. Dos métodos de ensino que se caracterizam para este trabalho estão considerados o RPG, o LARP, o Jogo de Papéis e a Contação de Histórias.

O RPG, que significa Jogos de Interpretação de Papéis, em uma livre tradução da sigla em inglês, segundo Schmit (2008) pode ser dividido em várias subcategorias, dependendo da maneira como os seus jogadores se dispõem a jogá-lo. Dessa forma, o método de jogo mais tradicional é o chamado RPG de Mesa, em que os jogadores se sentam em volta de uma mesa e munidos de lápis, papel e dados de diferentes números de faces participam de uma história que é contada por um destes jogadores, conhecido dentro da atividade como narrador ou mestre, em que precisam interagir e decidir os rumos que tomarão as suas personagens que são criadas especificamente para participar destes jogos. Existem também os jogos eletrônicos, caracterizados por videogames e jogos de computador, e os jogos chamados de Aventura-Solo, em que o jogador segue um texto descrito em um livro escolhendo opções que tornam a leitura não linear conforme as opções surgem no final de cada parágrafo indicando uma página diferente onde a história tem continuidade.

O LARP, que significa Jogo de Papéis ao Vivo, também numa livre tradução da sigla em inglês, segundo Bowman (2015) se caracteriza como jogos de interpretação muito parecidos com o RPG, mas que, ao invés de ser executado em volta de uma mesa ou atrás de uma tela de computador acontecem em ambiente aberto que funciona como um cenário, permitindo aos jogadores que interpretem de maneira mais livre as suas personagens, como se estivessem fazendo parte de uma peça de teatro, porém sem falas definidas e com as personagens montadas com a mesma dinâmica utilizada nos RPGs.

Os Jogos de Papéis são atividades interpretativas mais livres, sem se ocuparem das questões de construção de personagens existentes nos RPGs, e também sem contarem com a estrutura de regra normalmente presentes nestes jogos, que muitas vezes determinam a sorte ou azar das suas personagens conforme estas se engajam em situações conflitivas.

E, finalmente, as Atividades de Contação de História, segundo SEBRAE (2018), são aquelas nas quais o objetivo da atividade está em elaborar ou contar uma história já conhecida, utilizando-se de diferentes efeitos narrativos para tornar a história mais dinâmica e interessante para os participantes da atividade. Podem existir personagens a serem interpretadas para cada jogador, mas normalmente o narrador se encarrega das personagens principais desta atividade.

Tendo claro que a Metodologia de Construção de Vivências é uma metodologia de ensino, pois se estabelece como um conjunto de ações, procedimentos, técnicas e teorias (ARMSTRONG, 2012), e quais são os seus principais métodos de ensino, dentro do que Libâneo (1994, p. 152) compreende como o "meio pelo qual um professor busca trabalhar um conteúdo em sala de aula com os seus educandos e os objetivos referentes à aprendizagem de tal conteúdo", agora será descrito o trabalho delineado para o desenvolvimento desta metodologia e a busca pela verificação se desempenha o papel ao qual foi elaborada, de colaborar com a formação crítica dos educandos em relação a diferentes assuntos científicos trabalhados durante a atividade.

\section{METODOLÓGIA DA PESQUISA}

A Metodologia de Construção de Vivências foi aplicada em duas turmas do nono ano do Ensino fundamental anos finais, sendo uma pertencente a uma escola pública da cidade de Bandeirantes (nomeada como Escola A), localizada na região norte do Paraná, que foi representada por um total de 16 alunos, e uma escola da rede privada (nomeada como Escola B) localizada na cidade de Londrina, também localizada na região norte do Paraná, e que também contou com um total de 16 participantes. 
Os alunos foram convidados pelos pesquisadores acompanhados pela professora de ciências de cada turma, que, por sua vez, foi procurada em primeira mão pelos pesquisadores e elucidada sobre quais seriam as atividades que seriam desempenhadas durante o trabalho a ser efetuado com estes alunos.

Para ambas as turmas foi estabelecido que as atividades aconteceriam dentro de suas escolas, em uma sala de aula escolhida pela equipe pedagógica, e que as mesmas aconteceriam no período da tarde, o que caracterizou para estes alunos uma atividade de contraturno, uma vez que todos eles frequentaram as suas escolas durante o período matutino, e as equipes pedagógicas não queriam comprometer as suas aulas regulares com a atividade, permitindo, portanto, que as mesmas acontecessem em um período diferente. As atividades aconteceram durante o segundo semestre de 2017, sendo que com os alunos da Escola A participaram das atividades durante os meses de agosto e setembro, e os alunos da escola B durante os meses de outubro e novembro.

O método de ensino escolhido para a aplicação da atividade foi o RPG de Mesa, que é uma modalidade de RPG na qual os jogadores utilizam papéis para anotar as características da sua personagem, dados para determinar as questões probabilísticas de sucesso ou fracasso das suas ações e um dos jogadores se mantém como o narrador, contando a história (SCHMIT, 2006). Cada aluno participante desenvolveu uma personagem por meio das regras explicadas pelos pesquisadores. Esta personagem foi sendo elaborada desde o primeiro encontro, sendo formalizada a sua construção no terceiro encontro, quando foram desenvolvidas as fichas de personagens, documentos nos quais os alunos podiam descrever as suas personagens e estabelecer as suas qualidades e fraquezas que seriam essenciais para o desenvolvimento da história.

Estas personagens foram pensadas para uma história de ficção científica que se passava em Marte, no ano de 2050. Os alunos foram incumbidos de criarem personagens cientistas que precisavam lidar com a implantação e manutenção de uma colônia no Planeta Vermelho, precisando durante as oito partidas desenvolvidas e pensadas para abarcar um tempo específico dentro da história, lidar com as mais diferentes adversidades, como a ocorrência de crimes entre os moradores da colônia e a queda de meteoritos sobre a estrutura física da colônia. Estas partidas marcavam histórias interligadas, com as ações dos alunos e das suas personagens sempre determinando o desenrolar da aventura e do comportamento das personagens controladas pelo professor-narrador, conhecidas no RPG como Personagens não Jogadores (PnJ).

Tanto os alunos da Escola A como da Escola B jogaram com a mesma história, sendo que cada partida era estruturada para abordar temas específicos que, com o desenvolvimento do jogo, iriam determinar a situação das personagens e do cenário durante as partidas seguintes. A primeira partida foi feita como uma discussão sobre a exploração espacial, sua viabilidade e os seus perigos. Cada turma foi dividida em dois grupos em que cada grupo precisou se posicionar a favor ou contra a viagem espacial e defender o seu posicionamento.

A segunda partida foi elaborada para explorar a questão da viagem espacial. Os alunos realizaram os cálculos da viagem da Terra para Marte e tiveram que resolver a situação do tempo que passariam ativos no espaço enquanto a nave se deslocaria de um planeta até o outro. Chegando até a colônia eles também teriam que lidar com alguns problemas iniciais, como a questão da horta comunitária estar produzindo apenas vegetais que crescem em solo muito ácido e também a superpopulação de pessoas e de cães.

Na terceira partida, onde estes alunos desenvolveram as fichas de personagens, e a história se passou em um tema investigativo, em que as personagens tiveram que desvendar um crime realizado contra os agricultores da colônia.

Na quarta partida uma situação-problema foi utilizada para abordar temas específicos de Física. Um meteoro foi detectado vindo em direção a bases auxiliares da colônia e os alunos tiveram que calcular quanto tempo teriam para salvar os pesquisadores presentes nestas bases. 
A quinta partida teve um caráter investigativo, conforme as personagens precisavam inquirir sobre a produção de drogas adulteradas na colônia. Os alunos se depararam com a situação de que os mineradores da colônia estavam envolvidos com a questão do tráfico de drogas e assim as suas personagens se viram obrigadas a investigar as minas escavadas perto da colônia, configurando um tipo de jogo chamado de Exploração de Masmorras (WITWER, 2016), considerado um dos tipos de aventuras mais clássicas para RPGs de mesa.

Na sexta partida um novo meteoro surgiu em direção à colônia, e dessa vez o seu curso indicava que a colisão se daria com a colônia principal. Novamente os alunos precisaram realizar novos cálculos para determinarem quanto tempo teriam para lidar com a situação e, também, para determinar se o escudo de força da colônia conseguiria absorver toda a energia gerada pelo impacto do meteorito.

Na sétima partida os alunos tiveram que lidar com o acidente do meteoro da partida anterior, que gerou caos generalizado na colônia, aumentando o número de crimes e assassinatos. Os alunos também tiveram que lidar com questões de corrupção na qual algumas das personagens estiveram envolvidas e que indiretamente contribuíram para a balbúrdia que se instalou na colônia. A oitava e última partida foi realizada para amarrar todos os nós soltos da história e determinar se as personagens conseguiriam voltar para casa.

Para registrar as atividades desenvolvidas durante estas oito partidas realizadas com os alunos da Escola A e com os Alunos da Escola B, foram determinados três instrumentos para a coleta de dados. O primeiro instrumento foi a elaboração de um relatório de atividades que cada aluno ficou responsável em produzir a cada partida na qual participava, descrevendo as situações pela qual a sua personagem havia passado como um caráter informativo para o comando espacial localizado na Terra. O segundo instrumento foram as próprias fichas de personagens que possuíam muitas informações escritas pelos alunos. O terceiro instrumento de coletas de dados foi uma entrevista realizada com cada aluno participante, feita com questões semiestruturadas, que tinham como objetivo perceber os principais elementos considerados essenciais para a formalização da Metodologia de Construção de Vivências.

Para realizar a leitura dos dados obtidos por meio dos instrumentos utilizados optou-se pela utilização da Análise de Conteúdo (BARDIN, 2004) em que, por meio da formação de um Corpus de pesquisa presente em cada uma destas fontes de informação, foi possível desenvolver quatro Categorias de Análise que permitiram uma interpretação da atividade realizada em cada um dos três documentos analisados e o entendimento de como esta contribuiu para os objetivos esperados pelo trabalho. Os resultados da análise serão apresentados em uma tabela com valores percentuais, que serão interpretados e discutidos na sessão seguinte.

\section{RESULTADOS E DISCUSSÃO}

Como para este trabalho foi utilizado três Corpus diferentes para se realizar a análise de conteúdo, cada um exigiu um tratamento diferenciado para se adequar à compreensão daquilo que poderia emergir da pesquisa e para a busca do que Bardin (2004) conceitua como Unidades de Análise que, por sua vez, ao serem agrupadas, permitem emergir as Categorias de Análise que são os elementos estruturadores da discussão da pesquisa e que fornecem o entendimento daquilo que se conseguiu alcançar neste trabalho.

O primeiro documento analisado foram os relatórios elaborados por cada aluno após cada partida jogada. O primeiro relatório elaborado tanto pelos alunos da Escola A quanto pelos alunos da Escola B foi no formato Carta de Apresentação, que era basicamente um documento no qual estes alunos, escrevendo como se fossem suas personagens, explicavam para a Agência Espacial o porquê seriam importantes dentro da colônia espacial marciana. Os relatórios desenvolvidos a partir da segunda até a sétima partida tiveram um caráter de documento informativo, em que os alunos precisavam, sempre escrevendo como se fossem suas personagens, relatar para a Agência Espacial tudo 
o que acontecesse na colônia durante um determinado período de tempo que equivalia dentro do jogo a cerca de um mês. Um fator importante a ser considerado é que, enquanto a atividade com cada escola durou cerca de dois meses, dentro do jogo a história considerou uma passagem de um ano dentro da colônia espacial. O oitavo e último relatório foi feito como um documento final, em que cada aluno emitia um parecer da sua personagem sobre a viabilidade da colônia e a sua opinião sobre a exploração espacial.

Os alunos da Escola A tiveram um peso um pouco menor para a realização desta análise, pois acabaram produzindo um número muito baixo de relatórios, no total 22, enquanto os alunos da Escola B desenvolveram no total 64 relatórios. Esta perspectiva de contribuição de cada parte pode condizer com o que Garcia (2013) alerta como sendo resultado das discrepâncias encontradas nas escolas públicas e privadas desde o final da década de oitenta, onde os alunos da escola pública têm se mostrado cada vez menos interessados e preocupados com a participação em atividades de ensino e aprendizagem, tanto dentro como fora da sala de aula, e os alunos das escolas privadas se mostram mais participativos e interessados. Fazendo uma leitura destes 86 documentos foi determinado que as unidades de análise seriam as falas que estivessem implicadas com ações que instituíssem alguma resolução que afetasse a partida. As falas muitas vezes adotavam posturas passivas, conforme os alunos descreviam situações conduzidas pelos pesquisadores e que estes concordassem, como posturas ativas, quando os próprios alunos por meio das suas personagens agiam no intuito de resolver as proposições apresentadas durante a partida. Decidiu-se, portanto, com a elaboração de quatro Categorias de Análise, que estão descritas a seguir:

a) Vivenciamento: Esta categoria se fez devido às unidades de análise que apontavam para a ação ativa dos alunos resolver uma situação-problema, valendo-se da experiência que vivenciavam durante o jogo e que contribuía para a elaboração de respostas para situações com as quais poderiam não estar acostumados e que, graças a experiência proporcionada pelo jogo, conseguiram desenvolver em seus relatórios.

Algumas falas que representam esta categoria:

- "Quando o meteoro atingiu uma das colônias, todos nós tentamos ser os mais rápidos possível para que todos ficassem bem"

- "Encontrar um meio de enriquecer a plantação da colônia"

- "Impedir que dois meteoros destruíssem a base", "achar um meio de alimentar a todos após o choque"

- "E também precisamos conversar com os moradores para que se acalmassem antes da nave chegar"

- "Infelizmente tivemos problemas com a falta de nutrientes", "e tivemos que nos alimentar com nossos cachorros"

- "Sugerimos a criação de instituições de ensino"

b) Imersão: Esta categoria emergiu conforme se percebeu que algumas das falas dos alunos estavam mais relacionadas com o seu processo de imersão no jogo, buscando cada vez mais interpretar suas personagens e se destacar por meio de ações individuais que auxiliassem com o andamento da história.

Algumas das falas que representam esta categoria:

- "Eu, biólogo John, me reuni junto a mais colegas cientistas para desvendarmos o mistério da água envenenada com metal pesado"

- "Eu quero ir para a NASA passear"

- "Olá NASA, estou aqui para reportar a vocês sobre o ocorrido"

- "No último encontro eu fui responsável por contribuir na solução dos problemas referentes à população de crianças na colônia"

- "Eu fiz parte do grupo 1 onde era responsável pelo cuidado da horta"

c) Ludicidade: Esta categoria emergiu conforme se percebeu nas falas dos alunos resoluções tomadas para se cumprir com as determinações do jogo e seguir o planejamento da história, 
sendo muitas vezes conduzidas pelos pesquisadores e recebidas pelos alunos que as aceitavam de forma burocrática e constitutiva da atividade na qual estavam inseridos.

Algumas das falas que representam esta categoria:

- "Quando finalmente entramos, havia muitos problemas técnicos que dificultaram ainda mais nosso trabalho"

- "Infelizmente nosso capitão veio a falecer por motivo desconhecido"

- "Esperamos ansiosamente pela chegada da próxima nave"

- "Hoje fomos separados em grupos"

- "Cada um destinado a resolver um problema da colônia"

- "Foi realizado uma troca de profissão para Jason que passou a ser agricultor e aprender a felicidade dentro de si"

d) Culturalidade: Esta categoria emergiu conforme notou-se nas falas dos alunos conhecimentos e saberes que estes já traziam consigo e utilizavam para que as suas personagens conseguissem solucionar os desafios que se apresentavam a cada partida jogada.

Algumas das falas que representam esta categoria:

- "Nós usamos casca de ovo e banana para fertilizar nosso solo";

- "Para neutralizarmos o solo usamos cal"

- "Para nutrir o solo usamos fezes caninas, cascas de batata e abacaxi"

- "Ps. Quase morremos kkk Potássio! Potássio! Potássio!".

- "Coletamos as digitais presentes no pedaço de aço e de cada ferramenta, aquela com as mesmas digitais do pedaço, seria o usado pelo elemento"

- "Sári entra em uma sala com luz vermelha e uma bateria que sustenta uma plantação com 50 pés de Cannabis"

Após agrupar as unidades de análise e estabelecer estas quatro categorias, chegou-se a seguinte configuração, exposta a seguir na Tabela 1.

Tabela 1: Categorias de Análise dos Relatórios

\begin{tabular}{|c|c|c|c|}
\hline Categorias de análise & Escola A & Escola B & $\begin{array}{c}\text { Total por } \\
\text { Padrão }\end{array}$ \\
\hline Vivenciamento & $38(20 \%)$ & $187(28 \%)$ & $225(26 \%)$ \\
\hline Imersão & $61(32 \%)$ & $109(16 \%)$ & $170(20 \%)$ \\
\hline Ludicidade & $46(24 \%)$ & $270(41 \%)$ & $316(37 \%)$ \\
\hline Culturalidade & $45(24 \%)$ & $97(15 \%)$ & $142(17 \%)$ \\
\hline Total por Escola & 190 & 663 & 853 \\
\hline
\end{tabular}

Fonte: Os Autores.

Em relação à Tabela 1, mesmo que os resultados encontrados para Escola A seja bem mais baixa que a da Escola B, ainda assim foi possível realizar uma leitura dos resultados e compreender que em relação aos alunos da Escola A, a possibilidade de imergirem no papel das suas personagens foi uma atividade significativa para os mesmos, mais até do que a questão do jogo em si. Aquele foi um momento no qual estes alunos puderam pôr em prática toda a aprendizagem que vinham recebendo de sua professora de ciências durante aquele ano letivo, o que também fica evidente quando olhamos para os demais resultados. O capital cultural neste caso foi aquele adquirido em sala de aula e que, por meio da estrutura do RPG pode vir à tona enquanto as situações-problemas eram trabalhadas e resolvidas.

De acordo com a Tabela 1 percebeu-se na Escola B um desenvolvimento diferente, mais centrado na liberdade de ação e na possibilidade de explorar as oportunidades trazidas pelo RPG. Estes alunos vivenciaram o jogo em todos os seus aspectos e conforme se deparavam com as situaçõesproblema, buscavam resolver as mesmas perante as experiências pelas quais passavam. Fica claro que cada turma teve um desempenho e uma linha de ação diferente para lidar com as dificuldades que 
foram inseridas na história, lembrando que eram sempre os mesmos desafios para cada turma. Enquanto os alunos da Escola A resolveram estes desafios por meio da interpretação intensa das suas personagens e do conhecimento que haviam adquirido nas aulas tradicionais de ciências, os alunos da Escola B se permitiram vivenciar o jogo e experimentar todas as possibilidades conforme estas iam se apresentando.

O segundo documento analisado foram as Fichas de Personagens desenvolvidas por cada aluno que participou da atividade. Nestas Fichas os alunos determinaram os atributos nos quais as suas personagens eram boas ou ruins, além da descrição das personagens, uma breve história sobre as mesmas e também podiam desenhar a aparência delas ou um símbolo que as representasse.

O Corpus do segundo documento analisado foi composto por 32 fichas de personagens, sendo 16 pertencentes aos alunos da Escola A e 16 aos alunos da Escola B. Para se determinar as unidades de análise foram consideradas todas as informações contidas neste documento. Primeiramente realizando o que Bardin (2004) chama de Leitura Flutuante e posteriormente se agrupando as unidades de análise novamente em quatro categorias, estabelecidas a posteriori, as fichas de personagens permitiram estabelecer estas categorias que emergiram dos resultados da seguinte maneira:

a) Padrão Vivenciado: Esta categoria baseou-se no que no RPG de Mesa são chamados atributos, características que definem o quanto uma personagem faz bem ou não uma determinada tarefa. Os quatro atributos estabelecidos para o jogo que diziam respeito ao que os diferentes personagens poderiam realizar durante as partidas eram: Biologia, Astronomia, Gestão Espacial e Filosofia. Dessa forma, como unidade de análise para esta categoria foram considerados tanto os atributos que possuíssem um valor de 9 ou 10 (os valores variavam de 5 a 10), e também os gastos em pontos de experiência realizados pelos jogadores, que demonstravam interesse em serem mais eficientes nos momentos da história que exigissem conhecimentos que estavam ali sendo trabalhados durante as partidas.

b) Padrão Imersivo: Esta categoria foi estabelecida por meio da descrição da personagem, levando-se em consideração as diferentes características que cada aluno imaginava no anseio de construírem personagens únicas dentro da história. Dessa forma, levou-se em consideração as descrições mais simples como: peso, altura, cor dos cabelos e dos olhos da personagem; assim como características mais prosaicas do tipo: bom em judô; consegue dobrar o dedo para trás; poderosa, dentre outras.

c) Padrão Lúdico: Esta categoria se baseou no uso dos dois atributos padronizados para serem usados por todos os jogadores durante as partidas: percepção e atletismo. Estes atributos, diferentemente dos outros quatro incluídos dentro da categoria experimental, eram basicamente úteis para a realização de desafios específicos dentro da história, como lutar contra os inimigos, encontrar pistas indiretas que não poderiam ser descobertas com nenhum dos atributos específicos, não ser pego de surpresa por algum possível agressor e assim por diante. Além destes atributos também foram considerados como unidade de análise as fichas de personagens que continham no campo apropriado um desenho relacionado com a personagem e um nome que fosse diferente do nome do jogador, pois isso configura uma concepção clara de que este jogador compreendeu um dos princípios da atividade narrativa, a separação entre ele e sua personagem.

d) Padrão Cultural: Esta categoria foi estabelecida a partir da leitura das histórias criadas por cada jogador para a sua personagem. Os pesquisadores perceberam um padrão instituído neste campo da ficha de personagem que foi o que os jogadores imaginavam que era necessário para que elas pudessem pertencer ao jogo. Com essa compreensão eles estipularam seus locais de origem, ou seja, os países em que nasceram e que viviam antes que fossem enviadas para a missão espacial.

Ao separar estas quatro categorias e contar as unidades de análise presentes em cada uma, chegase ao resultado representado na Tabela 2. 
Tabela 2: Análise das Fichas de Personagens.

\begin{tabular}{|c|c|c|c|c|c|}
\hline Escolas & $\begin{array}{c}\text { Padrão } \\
\text { Vivenciado }\end{array}$ & $\begin{array}{c}\text { Padrão } \\
\text { Imersivo }\end{array}$ & $\begin{array}{c}\text { Padrão } \\
\text { Lúdico }\end{array}$ & $\begin{array}{c}\text { Padrão } \\
\text { Cultural }\end{array}$ & $\begin{array}{c}\text { Total por } \\
\text { Escola }\end{array}$ \\
\hline Escola A & $29(17 \%)$ & $73(43 \%)$ & $26(15 \%)$ & $41(24 \%)$ & 169 \\
\hline Escola B & $28(11 \%)$ & $112(45 \%)$ & $46(18 \%)$ & $64(26 \%)$ & 250 \\
\hline $\begin{array}{l}\text { Total por } \\
\text { Categoria }\end{array}$ & $57(14 \%)$ & $185(44 \%)$ & $72(17 \%)$ & $105(25 \%)$ & 419 \\
\hline
\end{tabular}

Fonte: Os autores.

A análise dos resultados da Tabela 2 indica que as Fichas de Personagem, tanto para os Alunos da Escola A, como os alunos da Escola B, focaram principalmente nas características que diziam respeito à construção da sua personagem, buscando assim desenvolver com profundidade a sua história e as características marcantes que os mesmos queriam que ficassem em destaque durante a partida. E assim, por exemplo, estes alunos puderam acessar aquilo que, sem dúvida, possuem maior familiaridade graças à sua inserção na cultura digital, que é a familiaridade com jogos eletrônicos, sejam eles de consoles de videogame ou de computadores, ou mesmo de jogos feitos para celulares, que é a construção de avatares, representações virtuais utilizadas para representar o participante de um jogo online.

A categoria Padrão Imersivo representada na Tabela 2 se destacou duas vezes mais que a maioria das demais categorias, demonstrando o empenho destes alunos em construir personagens que lhe parecessem atraentes e inseridos na história. A categoria Padrão Cultural se destacou em seguida, representando a construção da história das personagens graças aos conhecimentos que os alunos possuem do que consideram essencial para uma pessoa se tornar cientista e poder participar de uma exploração espacial. Interessante apontar que os alunos da Escola A citaram mais universidades estrangeiras, muitas vezes utilizando uma denominação ampla como "Universidade de Roma" ou "Universidade de Tóquio" ao mesmo tempo que vários deles preferiram utilizar como ponto de referência para a formação das suas personagens a universidade local, que muitos conhecem por já terem a visitado ou terem parentes que lá estudam. Os alunos da Escola B utilizaram mais universidades nacionais que possuem maior visibilidade, sendo que alguns também citaram universidades estrangeiras, apontando os nomes precisos como "Harvard" ou "Oxford" e nenhum deles utilizou a universidade local para esta construção.

As categorias Padrão Vivenciado e Padrão Lúdico se mostraram um pouco menos expressivos em relação as demais categorias, o que denota que os alunos possivelmente demoraram para compreender as regras do RPG e a utilização dos Atributos, se preocupando com os valores de pontuação mais para o final da atividade, mais especificamente entre a sexta e a oitava partida. Ainda assim é interessante notar o equilíbrio na distribuição de pontos dentro destes atributos, pois, segundo Ewalt (2016), em partidas de RPG de Mesa convencionais os jogadores se preocupam em customizar as suas personagens para torná-las poderosas, enquanto que em nossa atividade os alunos se preocuparam em manter suas personagens com habilidades equilibradas para poderem desempenhar bem os seus papéis na história.

Um valor que chama a atenção na Tabela 2 é o Padrão Cultural, em que os alunos da Escola B apresentou maior do que os alunos da Escola A. Infere-se que os alunos da Escola B podem ter parentes, amigos e/ou conhecidos que estão inseridos em atividades nas quais o saber científico é importante, como em laboratórios de pesquisa agronômica e da saúde, universidades e áreas técnicas e tecnológicas. Essa possível proximidade com tais pessoas se mostrou importante no momento de contar as unidades de análise que, estruturadas dentro da frequência ponderada, gerou, portanto, um maior valor.

O terceiro documento analisado neste trabalho foram as entrevistas realizadas com cada aluno que participou das partidas. Tais perguntas foram realizadas para se perceber como a participação no jogo poderia ter afetado a percepção dos alunos a respeito dos vários temas abordados e a percepção do seu desenvolvimento escolar e cultural após tal participação. Foram realizadas um total de 32 entrevistas que foram gravadas em áudio e depois transcritas ouvindo-se a fala de cada aluno e, por 
fim, digitando as mesmas por meio de um editor de texto. Estas entrevistas foram realizadas depois do encerramento das atividades e se constituíram das seguintes questões:

1. O que você entende por ciências?

2. Qual o assunto de ciências que você considerava o seu favorito?

3. Na sua opinião, o RPG ajudou a entender um pouco mais os assuntos relacionados a ciências?

4. Você já teve contato com temas relacionados com ciências fora da escola por meio de diferentes tipos de mídias, como livros ou revistas, filmes ou séries, jogos e outros?

5. Você consegue citar mídias específicas ou outras formas de contato que teve com temas científicos?

6. Você tem parentes que lidam com temas científicos diretamente ou indiretamente através da sua profissão ou interesses pessoais?

7. O que significa alguém ter o título de Doutor?

8. Como você se sentiu jogando com uma personagem que possui o título de Doutor?

As respostas formaram o Corpus que foi analisado e conforme as unidades de análise foram sendo determinadas, mais uma vez consideramos que as quatro Categorias de Análise poderiam ser mantidas, inclusive para permitir posteriormente uma análise comparativa entre os três documentos analisados. Cada Categoria de Análise foi dividida de acordo com as questões que produziram unidades de análise que se mostravam diretamente inerentes a estas categorias, sendo, dessa forma divididas da seguinte maneira:

a) Aprendizagem Vivenciada: As questões escolhidas para fazer parte desta categoria foram aquelas nas quais os alunos, por meio de suas respostas, demonstravam algum tipo de aprendizado advindo das partidas de RPG. Considerou-se aqui que, como um dos objetivos deste trabalho é demonstrar que a metodologia de construção de vivências também tem valor enquanto uma forma de se estabelecer a apropriação de determinados conteúdos e assuntos e a possível capacidade de pensamento crítico. Assim, as seguintes questões foram consideradas para estabelecer as unidades de análise:

1- O que você entende por ciências?

2- Qual o assunto de ciências que você considerava o seu favorito?

b) Aprendizagem imersiva: As questões escolhidas para fazerem parte de categorias de análises poderiam parecer mais apropriadas para outra categoria, como por exemplo, a que abrange o padrão cultural, pois estavam diretamente relacionadas com o entendimento dos alunos sobre o que é um título de doutor e/ou o que significa alguém fazer um doutorado. Porém, quando se leva em consideração que as questões 1 e 2 são complementares e que um dos objetivos do RPG era fazer com que os alunos se sintam como cientistas durante as partidas, considerou-se apropriado as questõesı e 2 serem agrupadas nesta categoria de análise e, portanto, as unidades de análise pontuarem aqui:

7- O que significa alguém ter o título de Doutor?

8- Como você se sentiu jogando com uma personagem que possui o título de Doutor?

c) Aprendizagem lúdica: Para esta categoria de análise foram consideradas as questões 3 e 4 que, de maneira direta ou indireta, remeteram os alunos a considerarem as partidas de RPG enquanto um método de ensino ao mesmo tempo em que este não deixava de ser uma atividade lúdica com características que geralmente estão implícitas neste tipo de atividade como "divertida", "desafiadora" ou "cultural" e, em muitos casos, agregadoras quando se leva em consideração os seus aspectos sociais e capacitadores para a compreensão de regras, sistemas e moralidade.

3- Se para ele o RPG ajudara a entender um pouco mais os assuntos relacionados a Ciências;

4- Se o aluno tinha contato com temas relacionados com Ciências fora da escola por meio de diferentes tipos de mídias, como livros ou revistas, filmes ou séries, jogos e assim por diante. 
d) Aprendizagem Cultural: As Questões que forneceram as unidades de análise como pontuação desta categoria de análise estavam bem explícitas e exigiram menos em termos de se compreender a totalidade das respostas. Nesta categoria em especial, a negativa na questão 6 resultou em zero pontos para o aluno que fornecesse tal resposta:

5- Você consegue citar mídias específicas ou outras formas de contato que teve com temas científicos?

6- Você tem parentes que lidam com temas científicos diretamente ou indiretamente através da sua profissão ou interesses pessoais?

A análise das entrevistas, por meio das unidades de análise que se configuraram como respostas completas, respostas parciais, ou respostas nulas, exigiu um tratamento diferenciado dos dados para que os valores encontrados fizessem sentido para este trabalho. Desta forma foi determinado para a análise um padrão de pontuação, estabelecida conforme a participação do aluno e o nível de aprendizagem que ele demonstrava ter conseguido a partir de suas respostas em relação ao questionário montado e pensado nas atividades feitas por meio do RPG. Assim sendo, destas unidades foram estabelecidas o seguinte padrão:

- Zero pontos: Quando o aluno não sabia dar uma resposta para a pergunta ou simplesmente não a respondia ou mesmo quando se expressava de maneira evasiva ou caso apresentasse uma resposta simples negativa como, por exemplo, "Não sei dizer", "Sei lá", "não sei responder" e "Acho que não".

- Um ponto: Quando o aluno respondia de forma superficial ou extremamente sucinta, dando poucos detalhes sobre o que exigia a pergunta ou não deixando muito claro o seu entendimento sobre o que havia lhe sido perguntado, como, por exemplo, "Acho que Biologia", "Eu achei bem legal", "Acho que me ajudou sim" e "Eu gosto de Astrologia".

- Dois pontos: Quando o aluno formulava uma resposta que respondia completamente a questão, deixando claro que compreendia o que lhe fora perguntado e conseguia justificar a sua resposta, como, por exemplo, "Eu gosto de Biologia, pois sou fascinado por Biologia Marinha e Botânica, áreas que me interessam bastante", "Meu pai é Engenheiro Agrônomo e sempre está envolvido com coisas de Biologia, como os OGM" e "Eu achei muito importante os jogos de RPG, pois eles me fizeram entender muita coisa que eu tinha dificuldade, como as fórmulas de Física que usamos na escola".

Esta técnica de análise é chamada por Bardin (2004) como Frequência Modulada e é indicada para realizar análises que demonstrem uma variação significativa nas respostas. Conforme a pontuação foi estabelecida e somada, tornou-se possível desenvolver a Tabela 3, que demonstra o resultado abaixo:

Tabela 3: Análise das Entrevistas.

\begin{tabular}{|c|c|c|c|}
\hline Categoria de Análise & Escola A & Escola B & $\begin{array}{l}\text { Totais das } \\
\text { Categorias }\end{array}$ \\
\hline Aprendizagem Vivenciada & $41(28 \%)$ & $51(25 \%)$ & $92(27 \%)$ \\
\hline Aprendizagem Imersiva & $39(26 \%)$ & $51(25 \%)$ & $90(25 \%)$ \\
\hline Aprendizagem Lúdica & $42(28 \%)$ & $58(28 \%)$ & $100(28 \%)$ \\
\hline Aprendizagem Cultural & $27(18 \%)$ & $44(22 \%)$ & $71(20 \%)$ \\
\hline Total de Unidades de Análise & 149 & 204 & 353 \\
\hline
\end{tabular}

Fonte: Os autores.

Estas entrevistas apontaram que pode existir um equilíbrio em todos os aspectos desejados para esta atividade, se considerando os pressupostos teóricos mencionados acerca dos postulados referentes à Construção de Vivências. Ao analisar-se a Tabela 3 percebe-se que as quatro categorias possuem valores muito próximos, sendo que o Padrão Lúdico teve um pouco mais de destaque entre os alunos da Escola A e os alunos da Escola B. Entrevistas realizadas ao final das atividades nos permitem avaliar como a Construção de Vivências contribuiu no desenvolvimento do entendimento que estes alunos possuem a respeito das atividades desempenhadas por aqueles e aquelas que lidam 
com o desenvolvimento científico e tecnológico de nossa sociedade. Foi muito relevante também constatar que estes alunos possuem boas definições do conceito de ciências e se interessam pelos mais variados assuntos, apesar de que os Alunos da Escola A citaram muitos assuntos que foram trabalhados durante o seu ano letivo enquanto que os alunos da Escola B, por exemplo, citaram assuntos mais amplos como interesse.

Analisando-se os três documentos diferentes, percebe-se que há várias correlações entre as categorias de analise desenvolvidas, apesar de que cada uma seja condizente com o corpus do qual cada categoria emergia a posteriori. As primeiras categorias dos três documentos estão relacionadas com a vivência advinda por meio da participação da atividade realizada com os participantes, se aproximando com os postulados de Larrosa (2016) que versam sobre a necessidade do desenvolvimento das experiências e dos sentidos em qualquer atividade humana, no caso deste trabalho, as atividades desenvolvidas em sala de aula. Em todas as atividades que foram desenvolvidas pelos alunos, as experiências que foram surgindo conforme acontecia a interação com a história e com os demais participantes oportunizavam o surgimento de ações, ideias e ressignificações que versavam com a possibilidade destes alunos de desenvolverem um senso crítico por conta daquilo que acontecia a cada partida e que afetava a vida das suas personagens. Por meio das personagens que controlavam estes alunos tiveram a oportunidade de se aventurar em meio a conceitos científicos que, até então, seriam experimentados apenas por meio de teorias, que, por sua vez, estariam muito distantes das suas realidades e das suas vidas.

As segundas categorias advindas da análise dos três documentos se associam com a concepção de imersão, ainda que não esperado de início neste trabalho, o que demonstra uma atividade muito importante quando se utiliza jogos narrativos e interpretativos, que é a capacidade de se submeter às experiências que surgem durante as atividades, levando a busca do que Moreno (1997) caracteriza como Catarse, que é a capacidade de gozar do prazer de se conseguir uma conquista que, ainda seja efêmera, possui significado para aquele que a conquistou. Estes resultados apontam para uma possível participação da atividade com maior empenho por parte dos alunos, conforme apreciavam o desenvolvimento das suas personagens e o desenvolvimento da história em si.

As terceiras categorias advindas da análise dos três documentos estão diretamente relacionadas com a estrutura dos jogos utilizados durante as atividades. Como salienta Brougère (2010), o brincar está relacionado com o desenvolvimento social de cada indivíduo, conforme o lúdico permite este desenvolvimento social que está impregnado de regras e que possui uma estrutura que, espera-se, seja seguida por cada indivíduo dentro da sociedade. Huizinga (2014) reforça a necessidade da existência do Círculo Mágico conforme cada partida foi sendo jogada e novas regras foram sendo apresentadas, ou reforçadas para que os alunos se sentissem seguros dentro da atividade, compreendendo que aquelas regras permitiam o desenvolvimento de uma atividade que não fora meramente desenhada para ser didática, mas que aliava a possibilidade de se aprender enquanto se participava de um jogo em sala de aula.

Às quartas categorias encontradas a posteriori de cada um dos três documentos analisados estão alinhadas com o conceito de Capital Cultural apresentado e defendido por Bourdieu (CATANI et al., 2017), pois durante os jogos todos os conhecimentos que estes alunos já aprenderam durante a sua formação e vinham aprendendo durante o seu último ano no ensino fundamental foram essenciais para determinar o resultado de muitas escolhas e ações as quais tomavam durante as histórias. Quanto mais desenvolvido o seu capital cultural, mais fácil ficava se optar por um caminho a seguir.

\section{CONSIDERAÇÕES FINAIS}

Existe um consenso por parte de todos aqueles que se interessam em desenvolver uma disciplina de ciências que possibilite uma formação mais humana dos nossos alunos que as 
metodologias pautadas em métodos tradicionais de ensino e aprendizagem não permitem tal formação. Dentre as novas metodologias que se apresentam para contribuir com esta lacuna, a Metodologia de Construção de Vivências se dispõe a auxiliar no desenvolvimento de um pensamento crítico em relação aos conteúdos científicos e a capacidade de se compreender este pensamento científico não apenas em sala de aula, mas também fora dela, possibilitando que os alunos se apropriem de saberes que contribuam com a sua emancipação perante a sociedade tecnológica que se desenvolve mais e mais.

As atividades realizadas com os alunos da Escola A, uma escola da rede pública do Paraná, e com a Escola B, pertencente à rede privada deste Estado, permitem que se compreenda que os métodos narrativos e interpretativos podem ser desenvolvidos em cada espaço, respeitando-se as suas limitações e as suas realidades, contribuindo com o desenvolvimento destes alunos e conferindo aos mesmos a oportunidade de apreender conteúdos e ideias, podendo contribuir com outras metodologias e métodos de ensino. Tais contribuições vêm a somar com todas as outras que estão sendo realizadas atualmente por educadores e pesquisadores da área de ensino de ciências e ampliar as pesquisas realizadas com jogos narrativos e interpretativos, em especial o RPG e o LARP.

\section{AGRADECIMENTOS}

Os pesquisadores agradecem aos alunos, professores, membros das equipes pedagógicas das escolas de Londrina e de Bandeirantes que gentilmente concordaram em participar desta atividade de pesquisa conduzida dentro do trabalho de doutorado do programa de Pós-Graduação da Faculdade de Educação da Universidade de São Paulo. Também agradecemos ao programa de Pós-Graduação e aos seus professores e funcionários.

\section{BIBLIOGRAFIA}

ARMSTRONG, D. L. P. e BARBOZA, L. M. V. Metodologia do Ensino de Ciências Biológicas e da Natureza. $1^{\mathfrak{a}}$ Edição. Curitiba: Editora Intersaberes, 2012.

BARDIN, L. Análise de Conteúdo. $3^{\underline{a}}$ Edição. Lisboa: Editora Edições 70, 2004.

BIZZO, N. Metodologia do Ensino de Biologia e Estágio Supervisionado. ^ª Edição. São Paulo: Editora Ática, 2012.

BOURDIEU, P. Escritos da Educação. 16ª Edição. Petrópolis: Editora Vozes, 2015.

BOURDIEU, P. A Miséria do Mundo. 9a Edição. Petrópolis: Editora Vozes, 2012.

BOWMAN, S. L. e STANFORD, A. Educational Larp in the Middle School Classroom: a Mixed Method Case Study. National Association for Media Literacy Education (NAMLE), 2015.

BROUGÈRE, G. Brinquedo e Cultura. 8ạ Edição. São Paulo: Editora Cortez, 2010.

CATANI, A. M.; NOGUEIRA, M. A.; HEY, A. P. e MEDEIROS, C. Vocabulário Bourdieu. $1^{\underline{a}}$ Edição. Belo Horizonte: Editora Autêntica, 2017.

CHASSOT, A. Alfabetização Científica. 5a Edição. Ijuí: Editora Unijui, 2011.

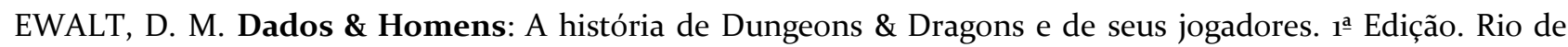
Janeiro: Editora Record, 2016.

GARCIA, P. S. Escolas Eficazes: uma descrição exploratória de duas instituições de realidades diferentes com bom empenho acadêmico. Em: BIZZO, N. e PELLEGRINI, G. Os Jovens e a Ciência. Curitiba: Editora CRV, 2013.

HUIZINGA, J. Homo Ludens. 8a Edição. São Paulo: Editora Perspectiva, 2014.

KRASILCHIK, M. Prática de Ensino de Biologia. São Paulo: Editora UNESP, 2004. 
LARROSA, J. Tremores: Escritos sobre experiência. 1ª Edição, Belo Horizonte: Editora Autêntica, 2016.

LIBÂNEO, J. C. Didática. ıª Edição. São Paulo: Editora Cortez, 1994.

MORENO, J.L. Psicodrama. 12a Edição. São Paulo: Editora Cultrix, 1997.

SCHMIT, W. L. RPG e Educação: alguns apontamentos Teóricos. Londrina: Universidade Estadual de Londrina, 2008.

SEBRAE. Storytelling na Educação: O poder das narrativas para estimular a atenção, a criatividade e as relações interpessoais em sala de aula. Livro Digital, 2018.

WITWER, M. Dungeons \& Dragons: O império da Imaginação. São Paulo, SP: Editora Leya, 2016.

Fernando Gianetti Fiorin Graduado em Ciências Biológicas pela Universidade Estadual de Londrina - UEL (2004), mestre em Genética e Biologia Molecular - UEL (2008), Mestre em Ensino de Ciências e Educação Matemática - UEL (2013), Doutor em Educação pela Universidade de São Paulo - USP (2019). Tem experiência na área de ensino de ciências e biologia, atuando nos temas: Formação Docente, Metodologia de Ensino de Ciências e Biologia e o Lúdico no Ensino de Biologia. Atualmente é professor temporário da Universidade Federal de Santa Catarina.

E-mail: fernandogianettifiorin@gmail.com

Agnaldo Arroio Graduado em Química pela Universidade de São Paulo - USP (1996), mestre em Química - USP (1999), doutor em Química - USP (2004), graduado em Imagem e Som: Produção Audiovisual pela Universidade Federal de São Carlos - UFSCar (2004), Pós-doutorado em Educação - USP (2005) e Livredocência em Educação pela Faculdade de Educação - USP (2011). Tem experiência na área de Química, Comunicação e Educação, atuando nos temas: Ensino de Química, Tecnologias da Informação e da Comunicação e Letramento Midiático. Atualmente é Professor Associado da Faculdade de Educação - USP. Orienta mestrado e doutorado e supervisiona pós-doutorado na FE-USP. Presidente da Organização Internacional para a Educação em Ciência e Tecnologia - IOSTE (2018-2020); Representante da América do Sul no Comitê Internacional - IOSTE - (2010-2012; 2012-2014). Diretor de Educação - Associação Brasileira de Química - ABQ (2013-2015, 2015-2017) e Diretor de Relações Internacionais (2017-2019), Coordenador do DINTER - UFPI - FEUSP (2015-2020). Professor Visitante: Universidade Siauliai - Lituânia (2016); Beijing Normal University - China (2019); Japan International Cooperation Agency - JICA em Moçambique (20132015). Colaborador da Universidade Virtual de São Paulo - UNIVESP (2016-2020). Editor-chefe da Problems of Education in the 21st Century e Membro de conselhos editoriais de revistas indexadas.

E-mail: agnaldoarroio@yahoo.com 